\title{
GÊNEROS TEXTUAIS: COMO ENSINÁ-LOS NO INTERIOR DAS PRÁTICAS DE LEITURA E ESCRITA?
}

\author{
Renata Amaral de Matos Rocha*
}

\section{Resumo}

Como usar os gêneros para ensinar leitura e produção de textos em sala de aula? Os textos são construídos dentro de um contexto, têm interlocutores, formato próprio, suporte específico, possíveis propósitos de leitura, ou seja, constituem-se pelas chamadas características sociocomunicativas, definidas pelo conteúdo, pela função, pelo estilo e pela composição do material a ser lido. E é essa soma de características que define os diferentes gêneros. No entanto, explorar apenas as características de cada texto contribui muito pouco para o desenvolvimento das habilidades de leitura e escrita de determinado gênero por parte dos nossos alunos. Por isso, objetivamos apresentar uma possibilidade de trabalho com os gêneros textuais de forma efetiva, real, no âmbito da sala de aula. Para tanto, discutiremos sobre quem escreve e para quem se escreve um texto, com que objetivo, em que contexto sociocomunicativo etc. Essa abordagem amplia o tratamento dado aos gêneros textuais sob a ótica da nomenclatura e forma, e representa um grande avanço no ensino das línguas, neste caso, da Língua Portuguesa.

Palavras-chave: Gêneros textuais. Notícia. Charge.

\section{INTRODUÇÃo}

Qual é o papel da escola no que diz respeito ao ensino de nossa língua materna? Acreditamos que é algo no âmbito da formação de cidadãos capazes de interagir com o outro e com mundo à sua volta, de modo adequado e competente, oralmente e por escrito, para que possam se inserir de pleno direito na sociedade e ajudar na construção e na transformação desta sociedade.

Para cumprir este papel, cabe à escola, então, criar condiçôes para que seus alunos desenvolvam habilidades para usar a língua nas mais diversas situações comunicativas reais e, também, propiciar uma constante reflexão sobre esses usos. Esse trabalho deve ser contextualizado e partir do conhecimento que os estudantes possuem, sobretudo no que tange à língua, que é aprendida e usada pelos indivíduos, em alguns contextos, antes do início da fase escolar. No entanto, para efetivamente alcançarmos esse objetivo, pensamos que

\footnotetext{
a educação precisa deixar de lado seu paradigma conservador de transmissão do conteúdo disciplinar e se voltar para a contemporaneidade, que está a exigir, cada vez mais, professores e alunos leitores e consumidores dos meios de comunicação, mas críticos e ativos, que saibam discernir acerca das informaçóes realmente relevantes e, a partir daí, tenham condiçóes de construir um conhecimento significativo (PAROLI; ALMEIDA JUNIOR, 2008).
}

Nesta perspectiva, o jornal se constitui como um valioso instrumento de trabalho para o professor de Língua Portuguesa, porque possui a palavra como objeto e atua como espaço para as seguintes atividades: aprendizagem de várias visões de mundo; conhecimento de uma série de assuntos, reflexão acerca da realidade do mundo e contato

Doutoranda em Estudos Linguísticos pela FALE/UFMG e professora efetiva no Centro Pedagógico da UFMG. E-mail: reamaral.teixeira@gmail.com

Instrumento: R. Est. Pesq. Educ., Juiz de Fora, v. 19, n. 2, jul./dez. 2017 
com diversos gêneros textuais. No momento em que se ouve ou se lê um jornal, o cidadáo passa a conhecer o contexto social e político do próprio lugar onde mora, e de outros lugares, e tem contato com alguns dos modos de materialização das informações.

Faria (2006) afirma que, através das atividades com jornais, na sala de aula, é possível estabelecer laços entre a escola e a sociedade, porque o jornal é um meio de comunicação e de divulgação de acontecimentos recentes que circula no dia a dia do aluno. A autora considera o jornal como exemplar suporte de textos, como fonte primária de informação, como formador do cidadão, auxiliar na formação geral do estudante, portador de textos autênticos e de registro da história corrente. Ratificamos esse posicionamento de Faria (2006) com dados de abordagem docente no ensino da Língua Portuguesa com e sem o uso do suporte jornal e seus gêneros. Percebemos que os estudantes tiveram maior engajamento nas atividades de leitura de textos de circulação real e que tiveram melhor empenho e desempenho na produção de textos para efetiva interação, como na proposta de se construir o "Jornal da Classe", que tinha o propósito de circular pela escola.

Em vista disso, objetivamos apresentar esta experiência de trabalho com o suporte jornal e com alguns dos gêneros textuais nele veiculados, de modo que possamos fomentar o trabalho do professor por esse viés sociointerativo real.

\section{O JORnal na sala de AUla}

$\mathrm{O}$ jornal enriquece as atividades de ensino e aprendizagem nas escolas, pois ele traz, diariamente, os fatos ocorridos na sociedade, bem como todo um conjunto de serviços que são de vital interesse de todo cidadão. Por isso, acreditamos que o uso do jornal durante as aulas estimula os educandos a refletirem sobre temas atuais, a exercitar as capacidades de atenção, síntese, comparação e análise, melhorando o poder de argumentação e o senso crítico dos estudantes, além de apresentar a eles uma diversidade de gêneros textuais.

No âmbito do jornal, os gêneros notícia e charge merecem ser trabalhados em sala de aula com bastante empenho e detalhamento. A notícia, gênero básico do jornal, relata um fato do cotidiano considerado relevante e é um gênero genuinamente informativo, no qual, em princípio, o jornalista não se posiciona, ou não deveria posicionar-se, pois o que vale é o fato. Segundo Faria e Zanchetta (2005), notícias são:

\begin{abstract}
informações sobre um acontecimento, considerado, por quem publica, importante ou interessante para ser mostrado a determinado público. Sobre esse fato são observadas, entre outras, as seguintes características, para se definir se ele é ou não é notícia: ineditismo, atualidade, veracidade e o potencial de importância ou interesse que ele pode ter para uma dada parcela da sociedade (FARIA; ZANCHETTA, 2005).
\end{abstract}

A charge, por sua vez, traz em seu âmago a marca da interdiscursividade, pois, ao transitar entre o discurso jornalístico e o discurso humorístico, ela acaba por assumir características de ambos. No entanto, é o tom jocoso que a torna diferente e, portanto, sedutora. Mais que isso, torna-a transgressora. Segundo Teixeira (2005), essa transgressão é positiva tanto para o jornal quanto para o leitor, pois é uma estratégia que proporciona a ambos uma subversão diária, "uma 'travessura' acima de controles e regras, além do tédio, da mesmice e da chatice do dia a dia" (TEIXEIRA, 2005, p. 14).

Com base nessas breves considerações, já se pode antever que o trabalho com textos jornalísticos pode gerar ricos desdobramentos em atividades de leitura, interpretação, reflexão e escrita de textos.

\subsection{A construçấo do teXto noticioso}

A notícia percorre um caminho antes de chegar ao leitor. Tem início com o repórter, que busca o fato; passa algumas vezes pelo redator, que ajusta o relato do 
repórter aos padróes do jornal. Em seguida, os editores decidem que lugar a notícia vai ocupar no jornal e, então, a versão final é publicada. Nesse percurso, os fatos da notícia são organizados por ordem de importância. Faria (2005, p. 26) esclarece que "o texto noticioso é uma forma de narração com modo próprio de organização". A linguagem da notícia precisa ser clara, a fim de ser compreendida por um grande número de pessoas; ser objetiva, evitando muitas caracterizaçóes e explicaçóes, focando apenas o fato corrido e seu contexto imediato. Também é necessário que o fato seja passível de comprovação, ou seja, que haja dados e/ou declaração de pessoas envolvidas no ocorrido.

Além de tudo isso, julgamos importante discutir com os estudantes a questáo da (im)parcialidade dos textos jornalísticos, conduzindo os alunos a perceberem que não há como usar a linguagem de modo imparcial. No entanto, podemos dizer que há níveis de (im) parcialidade e que, talvez, as notícias, no geral, tendam a ser construídas com menos marcas explícitas de parcialidade. Essa questão pode ser analisada e comparada, de jornal para jornal, de notícia para notícia, de redator para redator, de modo muito rico.

Para melhor compreensão do gênero notícia, apresentamos este quadro:

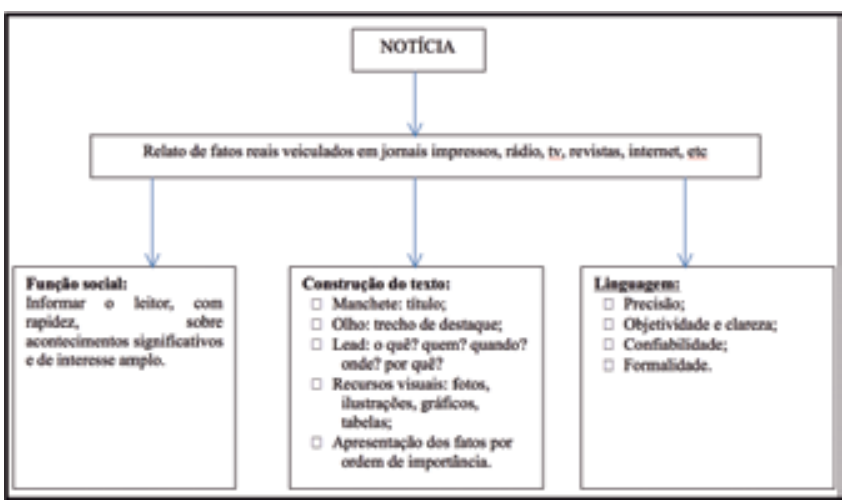

Quadro 1 - Esquema de construção do gênero textual notícia.

Fonte: Elaborado pela autora.

\subsubsection{Por uMa ABORDAGEM DIDÁTICO-PEDAGÓGICA DO GÊNERO TEXTUAL NOTÍCIA}

A notícia é um gênero textual muito presente no cotidiano da sociedade, pois as informaçóes acerca dos acontecimentos atuais circulam nos meios de comunicação diariamente e despertam o interesse da sociedade como um todo. Ao desenvolver um trabalho com notícias, em sala de aula, podemos analisar informaçóes sobre diversos assuntos, como economia, política, esporte, educação, saúde, de modo a desenvolver o senso crítico dos alunos diante de temas sociais e a orientá-los na compreensão da função social do gênero notícia, a partir do reconhecimento de pistas que comprovem que aquele texto tem a função de informar algo atual e que seja de interesse de um público amplo. Nesta perspectiva, tomemos como objeto de discussão esta notícia:

\section{RESTANDO ALGUMAS HORAS, CERCA DE 1,5 MILHÃO AINDA NÃO ENTREGARAM IRPF}

ENTREGA 'TRANSCORREU COM BASTANTE

TRANQUILIDADE', DIZ SECRETÁRIO DA RECEITA. FISCO ESPERA RECEBER 27 MILHÓES DE DOCUMENTOS; PRAZO ACABA ÀS $23 H 59$.

A Receita Federal informou que recebeu de seus contribuintes até as $17 \mathrm{~h}$ desta quarta-feira (30) cerca de 25,5 milhôes de declaraçóes de Imposto de Renda de Pessoa Física 2014. O Fisco espera 27 milhóes de documentos neste ano. Deste modo, aproximadamente 1,5 milhão de brasileiros ainda não enviaram a declaração.

O volume entregue neste ano, até às $17 \mathrm{~h}$ do último dia do prazo, é inferior ao registrado no mesmo período de 2013 (26,15 milhóes de documentos). A entrega, em 2014, começou no dia 6 de março e vai até as $23 \mathrm{~h} 59$ desta quarta-feira (30). Quem perder o prazo está sujeito a uma multa mínima de R\$ 165,74. O programa está disponível para "download".

"Tal qual vem ocorrendo nos últimos anos, a entrega transcorreu com bastante tranquilidade. Sem registro de nenhum problema. Tudo dentro da normalidade. Não teve 
congestionamento", declarou o secretário da Receita Federal, Carlos Alberto Barreto, a jornalistas.

Neste ano também está permitida a entrega por meio de tablets e smartphones desde o início do prazo legal. O Fisco informou que até $90 \%$ das declarações podem ser feitas com estes equipamentos.

Entretanto, apenas 24 mil declaraçóes foram entregues em 2014 por meio de dispositivos móveis. Apesar da novidade não ter sido muito utilizada, Barreto, da Receita, avaliou que houve um "salto significativo" em relação aos sete mil documentos entregues em 2013 por meio de tablets e smartphones.

Os contribuintes que enviaram a declaração no início do prazo, sem erros, omissóes ou inconsistências, recebem mais cedo as restituiçóes do Imposto de Renda - caso tenham direito a ela. Idosos, portadores de moléstia grave e deficientes físicos ou mentais têm prioridade. Os valores começam a ser pagos em junho de cada ano pelo governo e se estendem até dezembro, geralmente em sete lotes.

Segundo a Receita Federal, estão obrigadas a apresentar a declaração as pessoas físicas que receberam rendimentos tributáveis superiores a $\mathrm{R} \$$ 25.661,70 em 2013 (ano-base para a declaração do IR deste ano). O valor foi corrigido em 4,5\% em relação ao ano anterior, conforme já havia sido acordado pela presidente Dilma Rousseff.

\section{Texto 1 - Notícia}

Fonte: Disponível em: <http:/goo.gl/hZmAUH>, adaptado. Acesso em: 30 maio 2014.

A notícia em foco trata de um tema ligado à economia, a Declaração de Imposto de Renda de Pessoa Física e, portanto, é de interesse de uma parcela significativa da população trabalhadora.

Acreditamos que as habilidades de leitura e interpretação de texto podem ser trabalhadas a partir da identificação do fato que deu origem à notícia e da compreensão da situação de sua ocorrência, buscando inferir possíveis implicações, se houver. É importante observarmos que o primeiro e o segundo parágrafos da notícia em análise trazem todas as informações referentes ao fato: o quê? entrega da DIRPF; quem? Receita Federal; para quem? trabalhador contribuinte; quando? até as 17h desta quarta-feira (30); onde? no Brasil; Por quê? o prazo está finalizando. No terceiro parágrafo, temos um depoimento que expressa uma opinião, mas de um entrevistado, o secretário da Receita Federal. Esse depoimento está devidamente apresentado entre aspas e é um argumento que dá maior credibilidade ao fato noticiado, o que é relevante que os estudantes compreendam.

Os parágrafos seguintes trazem detalhes sobre o fato: possibilidade de entrega da declaração por meio de tablets e smartphones; percentual de pessoas que entregaram o documento por esses meios; comparação do uso dessa tecnologia para envio da declaração no ano passado e neste; critérios para restituição do imposto e período dessa restituição; definiçãao do grupo que está obrigado a declarar e percentual de reajuste da tabela que define o valor mínimo recebido para ser declarante. Esses detalhes, embora importantes, são opcionais, pois o que importa mesmo são as informaçóes contidas nos primeiros parágrafos, pois trazem os dados básicos sobre o fato a ser informado. No entanto, os detalhes, quando aparecem, devem ser considerados, pois, certamente, estão ligados a algum objetivo comunicativo.

Depois deste trabalho com o gênero notícia, é muito valioso que os estudantes se coloquem no lugar de um jornalista e que saiam em busca de um fato para ser noticiado, no espaço da escola ou do bairro. E que façam registros fotográficos, colham depoimentos e anotem todas as informaçôes para produção da notícia. Essa produção de texto pode ser veiculada no Jornal da Classe, por exemplo.

\subsection{A Construção do gênero textual CHARGE}

A charge é um texto e, como tal, possui elementos que caracterizam sua construçấo. Em se tratando da linguagem, a charge costuma associar linguagem verbal (texto escrito) e não verbal (desenhos, caricaturas, balóes, cores e traçados). Na ilustração, caricata ou não, embora comumente seja, os chargistas utilizam-se de traços específicos para enfatizar as características do personagem que está sendo caricaturado. É um gênero 
predominantemente imagético, utilizado para criticar fatos ou situaçóes, provocar o leitor a partir de crítica contundente ou expor uma atitude de protesto. Sua construção pode ser assim esquematizada:

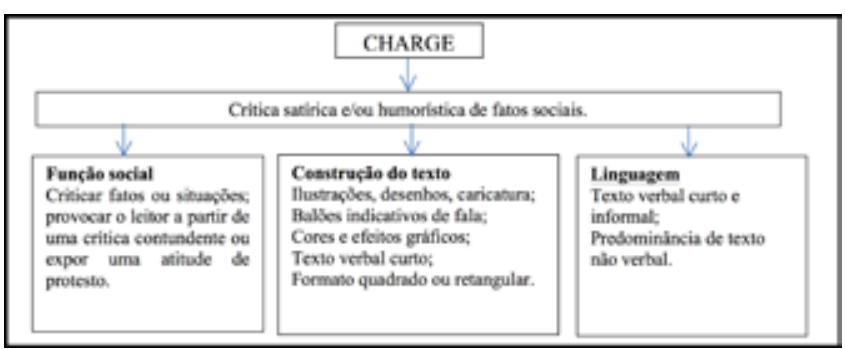

Quadro 2 - Esquema de construção do gênero textual charge.

Fonte: Elaborado pela autora.

\subsubsection{Por UMA ABORDAGEM DIDÁTICO- PEDAGÓGICA DO GÊNERO TEXTUAL CHARGE}

A charge é um tipo especial de cartum (maneira de emitir opiniáo sobre os acontecimentos do dia a dia). Ela tem por objetivo a crítica humorística e até satírica de um fato social. Para compreendê-la, é necessário conhecer o assunto a que ela se refere.

Para elucidar algumas formas de abordagem desse gênero em sala de aula, tomemos como objeto esta charge:

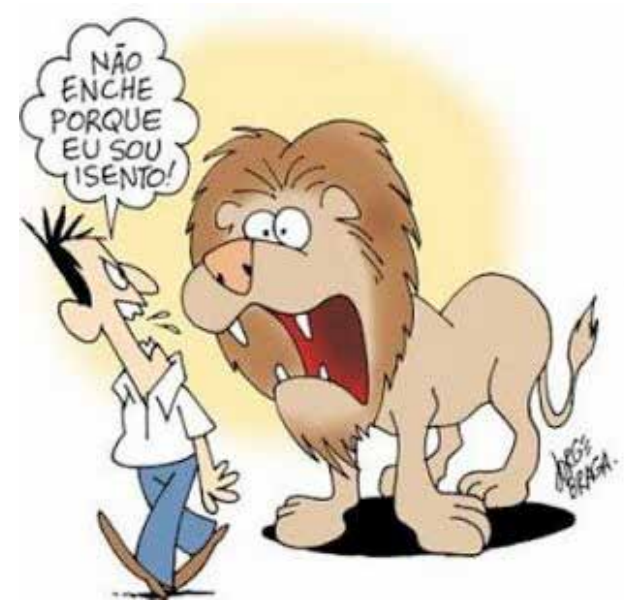

Figura 1 - Charge

Fonte: Disponível em: <http://goo.gl/hoxiKF>. Acesso em: 28 maio 2014.
$\mathrm{Na}$ charge em análise, o tema central é a Declaração de Imposto de Renda da Pessoa Física. Esse tema faz parte da vida de todo adulto, trabalhador e que tenha tido renda superior a $\mathrm{R} \$ 25.661,70 \mathrm{em} 2013$. É relevante notarmos que se trata de um público específico. $\mathrm{Na}$ charge, temos um pretenso indivíduo-declarante e a figura do leão, que representa o imposto de renda, o recolhimento do imposto, e que deveria imprimir uma sensação de medo. No entanto, ao contrário da notícia, essa charge nos surpreende ao apresentar a relação inversa: o leão mais frágil, frustrado, sem ação diante do indivíduo. Essa situação se configura porque o personagem humano da charge representa uma outra parcela da população, a dos isentos, palavra expressa no balão da charge. Esse grupo não paga imposto sobre a renda, alvo do leão. Logo, esse público não é alvo do leão.

O texto verbal é curto e informal, marcado, por exemplo, pelo uso do verbo "encher" em seu sentido figurado; já a construção do texto não verbal conta com o desenho de um ser humano como metonímia do grupo de pessoas que não declaram renda e ressalta alguns traços, como a saliva que sai de sua boca, para construir a imagem de quem esbraveja; temos, também, a caricatura do leão com ar abobalhado em oposição à figura do leão que ruge, que é forte e destemido, comumente ligado ao IRPF, etc. Todos esses elementos contribuem para que o chargista manifeste a sua opinião a respeito de fatos da vida real. $\mathrm{O}$ feito de sua composição é o humor (que se situa na força do homem frente ao leão) entremeado com a crítica (sobre o IRPF, imposto táo questionado).

No processo de interpretação da charge, tal como apresentamos acima, devem ser considerados alguns aspectos, tais como: o tempo e o espaço de construção do discurso chargístico; o conhecimento do assunto apresentado na charge; a identificação da pessoa ou da instância a que a charge se refere; o entendimento do 
traço, do exagero proposto pela caricatura, comumente presente no gênero; a relação entre linguagem verbal e não verbal; as cores, saliências e efeitos. Isso porque a leitura está para além da decifração, está para além, também, de uma simples descrição de imagens presentes na charge, porque esse gênero textual visa a crítica.

\subsection{GÊNeros teXtuais, Diálogos E POSI- CIONAMENTOS DISCURSIVOS}

Para enriquecermos o trabalho com os gêneros textuais notícia e charge, em sala de aula, pretendemos abordar mais três tópicos: o tema, o posicionamento diante do tema e o diálogo entre os textos. Para tanto, tomaremos como mote: o texto 1, notícia inicialmente analisada, intitulada "Restando algumas horas, cerca de 1,5 milhão ainda não entregaram IRPF”; o texto 2 , a charge 1, de autoria de Braga, e o texto 3, charge 2, de Son Salvador, apresentado abaixo.

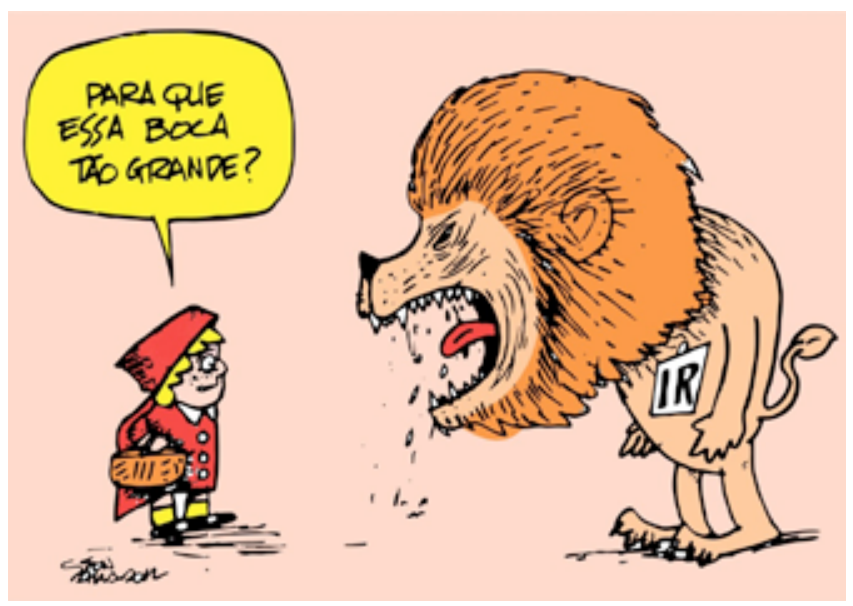

Figura 2 - Charge, SALVADOR, Son.

Fonte: Charge. Estado de Minas, BH, 27 abr. $2014^{1}$.

No processo em que se analisa o desenvolvimento do tema, é importante percebermos que há uma gradação entre o tema e os assuntos. Podemos entender que o tema tem uma significação mais ampla e pode se desdobrar em vários assuntos, que são recortes do tema.
O tema, necessariamente, acarreta um ponto de vista e dá margem à discussão. Nos três textos em análise, é possível percebermos que os três abordam o mesmo tema. A saber, a Declaração de Imposto de Renda de Pessoa Física.

$\mathrm{Na}$ notícia, o tema é claro e facilmente identificado, como podemos observar neste trecho:

A Receita Federal informou que recebeu de seus contribuintes até as $17 \mathrm{~h}$ desta quarta-feira (30) cerca de 25,5 milhóes de declaraçóes de Imposto de Renda de Pessoa Física 2014. O Fisco espera 27 milhôes de documentos neste ano. Deste modo, aproximadamente 1,5 milháo de brasileiros ainda não enviaram a declaração.

O fato que deu origem a essa notícia está explícito desde o título, o qual é retomado três vezes no mesmo parágrafo, indicados com grifos nossos, acima. Ao longo da notícia, esse tema é abordado e assuntos relacionados a ele são arrolados, tais como: expectativa do Fisco frente à entrega do documento, explicitada neste trecho da notícia: "O Fisco espera 27 milhóes de documentos neste ano"; estimativa de pessoas que ainda não enviaram a declaração, em: "aproximadamente 1,5 milhão de pessoas ainda não enviaram a declaração"; comparação do volume de entrega dos documentos nos anos de 2013 e 2014, em: "O volume entregue neste ano, até as $17 \mathrm{~h}$ do último dia do prazo, é inferior ao registrado no mesmo período de 2013"; data de início e término do processo de entrega da declaração, como em: "A entrega, em 2014, começou no dia 6 de março e vai até as 23 h59 desta quarta-feira (30)"; tipo de sanção para as pessoas que não cumprirem o prazo de entrega do documento, explicitada em: "Quem perder o prazo está sujeito a uma multa mínima de R \$ 165,74”; meios possíveis para entrega da declaração, como neste trecho: "Neste ano também está permitida a entrega por meio de tablets e smartphones"; avaliação do uso da tecnologia para entrega do documento, como nesta passagem: "apenas 24 mil declaraçóes foram entregues em 2014 por meio de dispositivos móveis"; e a forma de composição da tabela de 
restituição, de devolução de dinheiro para o contribuinte, como neste parágrafo:

\begin{abstract}
Os contribuintes que enviaram a declaração no início do prazo, sem erros, omissóes ou inconsistências, recebem mais cedo as restituiçóes do Imposto de Renda - caso tenham direito a ela. Idosos, portadores de moléstia grave e deficientes físicos ou mentais têm prioridade. Os valores começam a ser pagos em junho de cada ano pelo governo e se estendem até dezembro, geralmente em sete lotes.
\end{abstract}

Também foi abordado o perfil do cidadáo que precisa declarar o IRPF, como nesta passagem: "estão obrigadas a apresentar a declaração as pessoas físicas que receberam rendimentos tributáveis superiores a...", e o percentual de ajuste da tabela, que define o perfil econômico do contribuinte, como neste trecho: "O valor foi corrigido em 4,5\%".

É importante salientar que, nesta notícia, o tema foi explorado em seus vários assuntos, em ordem de importância para a composição do texto em análise, atendendo à forma tradicional de construção da notícia: o título, o olho, o lead, o detalhamento e a conclusão sobre o fato, que é o tema central do texto; mas essa forma não é uma receita, não é inflexível.

Nas charges apresentadas acima, também podemos perceber a abordagem do tema IRPF. No entanto, a compreensão do tema, o entendimento da charge, depende muito do conhecimento do leitor sobre o tema tratado, sobre o contexto em que a charge se insere, bem como da percepção do leitor sobre o humor, a crítica e/ou sátira que, certamente, há em um texto chargístico.

Para contextualizar, a caricatura do leão é o elemento que representa o tema IRPF nas duas charges, um elemento visual, próprio do gênero em análise. Segundo informaçóes do site da Receita Federal (<http://www.receita.fazenda.gov.br/Memoria/ irpf/curiosidades/curiosidades.asp $>$ ), o leão ruge pela primeira vez no final de 1979, quando a Secretaria da
Receita Federal encomendou uma campanha publicitária para divulgar o Programa Imposto de Renda. O leão foi imaginado como símbolo da ação fiscalizadora da Receita Federal e, em especial, do imposto de renda. De início, a ideia teve reações diversas, mas, mesmo assim, a campanha foi lançada. A escolha do leão levou em consideração algumas de suas características: é o rei dos animais, mas não ataca sem avisar; é justo, é leal, é manso, mas não é bobo.

As peças publicitárias começaram a ser veiculadas no início de 1980. A campanha resultou, de imediato, em uma identificação pela opinião pública do leão com o imposto de renda. Em dez anos, foram realizados cerca de trinta filmes.

O sucesso da campanha publicitária foi tão grande que chegou aos dicionários. O Houaiss define Leão como o órgão responsável pela arrecadação do imposto de renda. Segundo o Aurélio, Leão é o órgão arrecadador do imposto de renda. Para o Sacconi, Leão é o serviço de arrecadação do imposto de renda. $\mathrm{Na}$ definição do Dicionário da Academia Brasileira de Letras, Leão é o órgão encarregado de recolher o imposto de renda. Pelos conceitos emanados dos dicionários, verificamos a relação do Leão com o imposto de renda e não com a Receita Federal em si. Esse trabalho com o léxico e com o dicionário também é bastante produtivo, em sala de aula.

Também observamos que o que se liga ao felino é a arrecadação, embora, no início, a afinidade fosse forte com a fiscalização. Embora, hoje em dia, a Receita Federal não use a figura do leão, a imagem do símbolo ficou guardada na mente dos contribuintes, em uma das mais bem-sucedidas peças publicitárias da mídia brasileira. Explorar todas estas potencialidades na leitura de um texto (que vai além do texto em si), é muito importante para a formação dos nossos alunos como leitores críticos.

Diante dessas consideraçôes, podemos afirmar que as charges e a notícia apresentadas aqui versam 
sobre o mesmo tema: IRPF. Trata-se, portanto, de um diálogo entre esses textos, eles tomam elementos uns dos outros (e da sociedade em questão) e se apresentam em formas de comunicação diferenciadas: a notícia, um relato ancorado no factual, do domínio jornalístico; e as charges, da crítica, que mesclam o figurativo, o humor, a sátira e o jornalístico.

No entanto, é importante conduzirmos os nossos estudantes a perceberem que, embora os textos tratem sobre o mesmo tema, eles apresentam posicionamentos diferentes frente a ele.

A notícia, ancorada no fato (IRPF), aborda também assuntos relacionados a esse fato, com o intuito de informar o leitor sobre o processo de declaração de imposto de renda. Esse leitor faz parte de um público específico, pois nem todas as pessoas precisam declarar tal imposto. Segundo informado no último parágrafo da notícia em análise: "estáo obrigadas a apresentar a declaração as pessoas físicas que receberam rendimentos tributáveis superiores a R \$ 25.661,70 em 2013 (ano-base para a declaração do IR deste ano)". Como um gênero jornalístico, a notícia tem uma referência temporal (30/04/2014) e foi publicada no site do G1, um sítio de notícias. Com base em nossa análise desse site, essa notícia foi atualizada várias vezes, até o fim do prazo para entrega da declaraçáo, 23h59 do dia indicado, em uma tentativa de manter o leitor informado até o último minuto possível para se realizar a declaração. É como se "dissessem": se alguém perder o prazo de declaração, não será por falta de informação.

Por outro lado, as charges em análise, textos que transitam entre o humorístico/satírico e o domínio do jornalismo, tratam do mesmo fato da notícia analisada, ou seja, estabelecem um tipo de intertextualidade/ diálogo com ela. No entanto, as charges têm objetivos e posicionamentos discursivos diferentes da notícia.

A primeira charge traz uma pista linguística de categorização de grupos de declarantes. A palavra "isento", apresentada no baláo, indica que há grupos de pessoas que declaram o imposto e grupos que não declaram, que são isentas, e esse último grupo tende a ser exaltado na charge, quando o leão tende a ser rebaixado.

A imagem caricata do leão está diretamente relacionada ao grupo dos declarantes, pois é esse grupo que paga o referido imposto aos cofres públicos. E mais, é esse grupo dos declarantes/pagantes que comumente tem "medo" do leão, "por levar parte de sua renda embora". Diante disso, o leão da charge 1 tem um semblante frustrado e se mostra menos imponente, pois pressiona um cidadão que não se sente pressionado, pois faz parte do grupo dos não declarantes. Há uma inversão de posição nessa charge, o cidadão é que se mostra seguro, dono da situação e que "ruge" para o leão.

Ao contrário, na charge 2, o leão revela força, vigor, coragem, tenacidade frente ao seu interlocutor, que é a Chapeuzinho Vermelho. Esta charge também dialoga com a notícia, agora em termos de tema e posicionamento. Em ambos os textos, percebermos o tom de obrigatoriedade do ato de declarar tal imposto, a concepção de que os valores a serem pagos são altos, a noção de penalidade por uma possível não declaração e, sobretudo, a ideia de força do sistema frente ao indivíduo, que o "obriga ferozmente" a certas condutas.

Além disso, essa charge 2 dialoga também com outro gênero textual, o conto "Chapeuzinho Vermelho", por ser ela a interlocutora do leão, nesta charge, e proferir discurso semelhante a um determinado diálogo entre ela e o Lobo, no conto, inclusive com semelhança em termos de sentimento, o temor. Esse diálogo reforça a ideia de "perigo" da não declaração e do rombo que esses valores pagos ao governo causam em nossa renda. Nesta charge 2, então, o leão é comparado ao lobo do conto infantil, que é mau, injusto, ardiloso em suas condutas para conseguir alcançar seus objetivos, que, no caso do conto, é "comer a Chapeuzinho". Analogicamente, essa ação se compara à fatia de nossa renda, que é "comida pelo leão". 
Como podemos observar, o mesmo tema pode ser tratado em diferentes gêneros, que, por sua vez, podem exprimir posicionamentos semelhantes ou distintos sobre o mesmo fato. Essa construção da teia textual, nos gêneros analisados, dá-se pelas informações e pelos diálogos e intertextos neles costurados e articulados. Conduzir o processo de leitura dos estudantes, para que eles consigam fazer todas estas ligações, é de suma importância para a formação do leitor proficiente, crítico, o que, talvez, possa refletir em sua escrita, por ter mais informaçóes e compreender o texto de forma mais abrangente.

\section{CONSIDERAÇÓES FINAIS}

É evidente a necessidade de se implementar nas salas de aulas uma metodologia que verdadeiramente vise ao trabalho com a leitura e a escrita em suas acepções plenas. Nas palavras de Foucambert (1994), faz-se necessário uma visão de leitura como formulação de juízo sobre a escrita, um ato de questionar e explorar o texto na busca de respostas textuais e contextuais que geram uma ação crítica do sujeito no mundo.

O primeiro passo da escola pode ser: despertar o interesse do aluno pela leitura do jornal. Isso porque o jornal retrata a vida em seus mais variados aspectos. Inicialmente, seria interessante organizar um jornal escolar com notícias divulgadas pelos próprios alunos. Depois, vale levar para a sala de aula um jornal da cidade e realizar um debate acerca de determinadas notícias, de modo que a leitura e compreensão do jornal estejam sendo proporcionadas de modo eficaz e gradativo. $\mathrm{Na}$ sequência, passar ao diálogo com as charges, em uma tentativa de se contribuir para a construção do senso crítico do aluno.

Ao desenvolvermos este estudo, vimos que é possível trabalhar com as práticas de leitura, interpretação, escrita e reflexão linguística e de diálogos com o mundo em um mesmo texto, mostrando as múltiplas ligações que podem ser estabelecidas, além de se constituir uma prática docente abrangente, coerente, coesa e significativa.

\section{TeXt Genres: HOW TO TEACH THEM WITHIN THE PRACTICES OF READING AND WRITING?}

\section{Abstract}

How can we use genres to teach reading and writing in the classroom? Texts have specific size and support and possible reading purposes, they constitute the so-called sociocomunicative characteristics defined by content, function, style and composition of the material to be read. It is the sum of those features that define different genres. However, exploring only the characteristics of each text contributes very little to the development of reading and writing skills of certain genres by our students. It is necessary to discuss why and for whom a person writes a text, within a certain communicative context. That's the difference between treating genres as content itself and teaching them inside reading and writing practices.

Keywords: Text genres. News. Charge.

\section{GÉNEROS: CóMO LES ENSEŃAN DENTRO DE LAS PRÁCTICAS DE LECTURA Y ESCRITURA?}

\section{Resumen}

El uso de géneros para enseñar a leer $y$ producción de textos en el aula? Los textos tienen que tamańo, soporte específico, los posibles 
propósitos de lectura, es decir, constituyen las características denominadas sociocomunicativas definidas por el contenido, la función, el estilo y la composición del material que está siendo leído. Y es esta suma de características que definen los diferentes géneros. Sin embargo, sólo explorar las características de cada texto contribuye muy poco al desarrollo de las habilidades de lectura y escritura de ciertos géneros de nuestros estudiantes. Es necesario discutir qué y para quién se escribe un texto, dentro de un determinado contexto comunicativo. Esa es la diferencia entre el tratamiento de géneros como el contenido en sí y les enseñan dentro de las prácticas de lectura y escritura.

Palabras clave: Géneros de texto. Noticias. Cargo.

\section{Notas}

Charge adaptada por Glauber Bernardes Ferreira Rogério para a autora deste artigo, em 28 abr. 2014.

\section{REFERÊNCIAS}

BAKHTIN, M. Estética da criação verbal. São Paulo: Martins Fontes, 2003.

. VOLOSHINOV, V. N. Marxismo e filosofia da linguagem. Tradução Michel Lahud e Yara F. Vieira. 11. ed. São Paulo: Hucitec, 2004.

BRONCKART, J. Atividade de linguagem, textos e discursos: por um interacionismo sociodiscursivo. Tradução de Anna Rachel Machado. São Paulo: Educ, 1999.

DIONISIO, A. P.; MACHADO, A. R.; BEZERRA, M. A. (Org.). Gêneros textuais e ensino. São Paulo: Parábola, 2010.

FARIA, M. A. de O. O jornal na sala de aula. 13. ed., São Paulo: Contexto, 2004.

Como usar o jornal na sala de aula. 10. ed., São Paulo: Contexto, 2006.
FOUCAMBERT, J. A leitura em questão. Porto Alegre: Artes Médicas, 1994.

KOCH, I. V.; ELIAS, V. M. Ler e compreender: os sentidos do texto. 2. ed. SP: Contexto, 2008.

Ler e escrever: estratégias de produçáo textual. São

Paulo: Contexto, 2009.

MARCUSCHI, L. A. Gêneros textuais: definição e funcionalidade. In: DIONÍSIO, A. P.; MACHADO, A. R.; BEZERRA, M. A. (Org.). Gêneros textuais \& ensino. Rio de Janeiro: Lucerna, 2005.

MARTELLO, Alexandro. Restando algumas horas, cerca de 1,5 milhão ainda não entregaram IR". G1, 30 de abril de 2014. Disponível em: http://goo.gl/hZmAUH .Acesso em: 30 maio 2014

PAROLI, R. M.; ALMEIDA JUNIOR, J. B. Avaliação de programas de uso de jornal em sala de aula oferecidos aos professores por empresas jornalisticas. Anais... 29 . Reunião Anual da Anped. Disponível em: <http://www.anped.org. $\mathrm{br} /$ reunioes/29ra/trabalhos/trabalho/GT16-2236--Int.pdf>. Acesso em 10 de set. 2008.

TEIXEIRA, L. G. S. Sentidos do humor, trapaças da razão: a charge. Rio de Janeiro: Ediçôes Casa de Rui Barbosa, 2005.

Enviado em 06 de dezembro de 2016. Aprovado em 02 de setembro de 2017. 